\title{
The Journey to Creating Safety Net Accountable Care in New Jersey
}

\author{
Alexis Skoufalos, EdD and Kate Cecil, MS
}

\begin{abstract}
New Jersey's 3-year Medicaid Accountable Care Organization (ACO) Demonstration Project was the result of a bipartisan effort to address the quality and cost issues regarding the State's safety net population. The legislation sets forth a framework that allows communities to customize ACOs to meet the unique needs of their population. Camden, Trenton, and Newark are currently experimenting with implementation at various levels. This article documents the context, journey, challenges, and future direction of the legislation through the accounts of 7 stakeholders whose roles were integral in the process of its creation, marketing, and eventual implementation. Their individual perspectives serve not only as an historical record of events but also as a guide for states seeking reference for implementing their own ACO framework. (Population Health Management 2013;16:S-12-S-16)
\end{abstract}

\section{Introduction}

$\mathbf{I}$ N 2011, IN AN EFFORT to improve the health outcomes, quality, and access to care for its low-income population (Medicaid patients), and to lower public spending on health care, New Jersey signed into law a 3-year Medicaid Accountable Care Organization (ACO) Demonstration Project. [Note: From this point forward, the term "ACO legislation" will refer to the New Jersey Medicaid ACO Demonstration Project.] The demonstration was designed to provide an opportunity for communities to explore innovative system redesigns that will allow them to better serve Medicaid recipients, especially those that are their high-risk, high-cost utilizers of health care; expand Medicaid to integrate social services into the paradigm; and experiment with payment reform models utilizing pay-for-performance metrics and incentives. New Jersey communities interested in implementing ACOs must form a nonprofit organization that includes the participation of $100 \%$ of the hospitals, $75 \%$ of the primary care providers, and at least 4 mental health providers within their service region that serves a minimum of 5000 Medicaid beneficiaries. ${ }^{1}$

To date, 3 urban centers are seriously considering undertaking the New Jersey experiment. Camden and Trenton are already taking active steps to implement the ACO when the final regulations are issued, but Newark remains in the contemplative stage. Other New Jersey communities are beginning to organize to discuss and explore their options. The narrative in this article was developed from interviews with the primary stakeholders who helped to drive the development and passage of this groundbreaking legislation, in an effort to provide context, background, and information for other communities seeking to develop and implement innovative care delivery models (Table 1). Their accounts offer insight into the chronology, the political climate, the challenges experienced, and the lessons learned as the model for the New Jersey Medicaid ACO legislation evolved. The authors gratefully acknowledge their contributions to this article.

\section{Background and Political Climate}

New Jersey State Senator Joseph F. Vitale (D) and Thomas R. Wilson from Kaufman Zita Group report that the ACO legislation received unprecedented bipartisan support from the spectrum of stakeholders, including legislators and government officials, health care providers (individuals and institutions), patient advocacy groups, and leaders from health care and the general business community. The legislation created a shared savings program designed to provide resources to improve quality and coordination of care for Medicaid patients, with a special emphasis on management of high utilizers. The legislation was crafted in a manner to address antitrust issues that might otherwise prohibit this type of collaboration among providers.

The impetus to consider the ACO legislation was in large measure related to the tremendous financial pressures experienced in New Jersey, most particularly in consideration of the fact that the state includes urban centers that are home to some of its poorest citizens, many of whom have complex, chronic illnesses and are dependent on publicly supported health care. 
Table 1. Interviewee Names/Affiliations

John A. Brennan, MD, MPH-President and CEO, Newark Beth Israel Medical Center, Children's Hospital of NJ and Executive Vice President, Barnabas Health

Allison DeBlois-Executive Director, Affiliated Accountable Care Organizations, New Jersey Health Care Quality Institute

John V. Jacobi, JD-Faculty Director and Dorthea Dix Professor of Health Law \& Policy, Seton Hall University

David L. Knowlton, MA-President and CEO, New Jersey Health Care Quality Institute; former Deputy Commissioner, New Jersey Department of Health

Elizabeth Litten, JD-Partner, Fox Rothschild, LLC

Renee Steinhagen, JD, MA-Executive Director, New Jersey Appleseed Public Interest Law Center

Joseph F. Vitale-New Jersey State Senator (D) 19th Legislative District; Chairman of the Senate Health, Human Services and Senior Citizens Committee and Vice Chairman of the Senate Economic Growth Committee

Thomas R. Wilson-Partner, Kaufman Zita Group; Former Chairman, New Jersey Republican State Committee

Like the rest of the country, the general economic downturn starting in 2008 began to manifest problems described below that negatively affected health care delivery for vulnerable populations. New Jersey saw an increase in homelessness in its urban areas. There are significant challenges inherent in treating the health needs of homeless populations, particularly those whose physical health needs are often complicated by mental health or substance abuse problems. The costs associated with treating this largely underserved population can be substantial, and reimbursement rates have declined. A major flaw inherent in the system of care was a lack of incentives for providers to deliver high-quality, coordinated care. Emergency departments were utilized frequently, not only for acute needs but for nonemergency conditions; the majority of these visits could have been prevented or managed if Medicaid patients had timely access to good primary care. Care delivery was costly, episodic, and fragmented, and ultimately did not appropriately address the complex combination of social, economic, medical, and behavioral needs of this population. To continue doing "business as usual" was, at its core, financially unsustainable and not a viable option for any of the stakeholders-patients, care providers, or taxpayers (who are the payers in this circumstance). The aim of the legislation was to develop a value proposition for taxpayers based on lessons learned about how to incentivize and coordinate care for this population.

The overall goals of improving the quality of care, lowering costs, and enhancing revenue for providers through shared savings were appealing to the continuum of stakeholders. Those involved in receiving, providing, and paying for care all stood to benefit-if they worked together to achieve their common goals-and no group would benefit disproportionately at the expense of another. Politically speaking, it was easy to find proponents for the economic and social arguments, regardless of whether they leaned toward a conservative or progressive philosophy.

The stakeholders interviewed for this article unanimously credit the success of the legislation and its preliminary itera- tions to the efforts of Jeffrey Brenner, MD, executive director of the Camden Coalition of Healthcare Providers. Brenner was committed to addressing this national problem on a local level by bringing together stakeholders in a community-based governance model. In 2008, Brenner began examining the emergency department utilization patterns and associated inpatient admissions for Camden's Medicaid population. Identifying substance abuse, mental health pathology, and homelessness as key drivers of "superutilization," Brenner was committed to changing the paradigm and providing the type of preventive, coordinated care that ultimately would lead to better outcomes. Through identification and targeted, individualized intervention strategies, he developed low-cost, community-based, high-touch solutions that were having a positive effect on improving access, cost, quality of care (the vaunted Triple Aim) and, ultimately, health outcomes.

\section{Crafting the Legislation}

John V. Jacobi, JD, Renee Steinhagen, JD, and Elizabeth Litten, JD, attorneys who specialize in health care law, were recruited to craft legislation that would fit within the existing state/federal framework. They referenced previous state health care reform bills, such as the State Children's Health Insurance Program Medicaid expansion, in order to understand how money-saving quality improvement measures had been successfully initiated in the past. Their charge was to create something that would be acceptable to all parties; nurture development of local unit responsibility for specific areas and populations within a prescribed geographic scope; foster provider cooperation and engagement; and reduce or eliminate competition and duplicative services.

From the outset, the authors of the ACO bill sought to create a model that would be compatible with the existing health care delivery system, yet add an overlay of quality improvement. A shared savings model that provides incentives for delivering appropriate, quality care would help to assure the program's long-term financial sustainability. Before settling on the current model, the authors of the legislation reviewed New Jersey's Certificate of Need law and the New Jersey Maternal Child Health Consortia. The legislation is written in a manner that enforces a cooperative approach, and requires engagement from clinical providers with input from the patient population (community-based, shared governance model) (Table 2 and Figure 1). ${ }^{2}$ Unlike the feefor-service providers, whose participation was required under the legislative requirements, Medicaid managed care organizations (MCOs) could choose to be involved or not. Ultimately, Medicaid MCOs were supportive of the legislation because they were included in the dialogue, actively engaged in the conversation, and the ACO framework complemented their ideals. The Patient-Centered Medical Home (PCMH) model is embedded in New Jersey's ACO framework, as are some underpinnings of managed care.

The authors of the legislation chose its terminology very carefully; framing the initiative as a demonstration project enabled the state to support the flexible experimental model while operating under specific rules and processes. By design, there is sufficient flexibility to allow each community to develop a working model tailored to meet its unique economic, social, cultural, political, and medical needs-essentially, to deliver population-based health care. 
Table 2. Accountable Care Organization (ACO) Leadership Roles

\begin{tabular}{|c|c|c|}
\hline Role & Composition & Purpose \\
\hline Board of Directors & $\begin{array}{l}\text { A select group of influential health care and } \\
\text { community leaders, and other stakeholders. }\end{array}$ & $\begin{array}{l}\text { Oversees and provides general direction of } \\
\text { the ACO. Also supervises the manage- } \\
\text { ment team. }\end{array}$ \\
\hline Board-Level Committees & $\begin{array}{l}\text { Permanent committees made up of board } \\
\text { members and possibly appointees outside } \\
\text { the board. }\end{array}$ & $\begin{array}{l}\text { Provides oversight for specific ACO oper- } \\
\text { ational areas. }\end{array}$ \\
\hline Board Subcommittees & $\begin{array}{l}\text { Subcommittees can be standing (permanent) } \\
\text { or working (ad hoc) subsets of board-level } \\
\text { committees. Staffed by board members and } \\
\text { possibly appointees outside the board. }\end{array}$ & $\begin{array}{l}\text { Works on specific, narrow tasks as defined } \\
\text { by the larger committee. }\end{array}$ \\
\hline Management Team & $\begin{array}{l}\text { Paid staff members recruited for specific } \\
\text { functional roles. }\end{array}$ & $\begin{array}{l}\text { Manages the day-to-day operations of } \\
\text { the ACO, including care coordination/ } \\
\text { management, finance, legal, data } \\
\text { analysis/information technology, and } \\
\text { other activities. }\end{array}$ \\
\hline Community Advisory Board & $\begin{array}{l}\text { Residents, consumer advocates, and commu- } \\
\text { nity organizations. }\end{array}$ & $\begin{array}{l}\text { Provides community feedback to ACO } \\
\text { leadership. This advisory board is in- } \\
\text { dependent and not part of the board of } \\
\text { directors or the management structure } \\
\text { of the ACO. }\end{array}$ \\
\hline
\end{tabular}

Source: New Jersey Medicaid ACO Business Planning Toolkit. http://www.chcs.org/publications3960/publications_show.htm?doc_id= 1261530\#.UcDNY_nVA7k.

The bill was presented to fiscal conservatives as a budget issue wrapped with a "free market ribbon" around it. To social progressives, the legislation was appealing from the standpoint of improving critical health services to low-income and at-risk populations. For those who prioritized cutting health care spending, it was presented as a step toward entitlement reform; Medicaid was-and still is-an expensive line item in the state budget, with the top $1 \%$ of users responsible for a disproportionate percentage of the total cost. The legislation received enthusiastic bipartisan support as both parties recognized the severity of the problem. There also was a mutually expressed sentiment that the ACO be framed as a long-term legislative proposal in the form of a demonstration project rather than a 1-time budget bill in order to ensure widespread implementation and financial sustainability.

At its core, the ACO legislation emphasizes a bottom-up, grassroots approach at the community level. An initiative

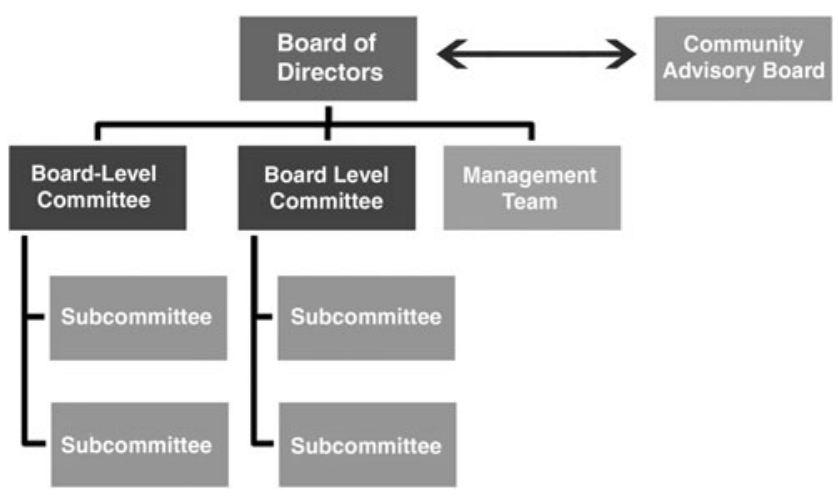

FIG. 1. Accountable care organization leadership structure. Source: New Jersey Medicaid ACO Business Planning Toolkit. http://www.chcs.org/publications3960/publications_show .htm?doc_id = 1261530\#.UcDNY_nVA7k. comprised of local efforts means each region can tailor its ACOs to suit its patients, providers, and payers. The absence of big government in this framework appealed to conservatives, while the social implications of improving health care for the poorest citizens of the state appealed to progressives. This alignment of incentives and values and the level of active engagement across so many stakeholder groups contributed to the success of the bill.

\section{Challenges}

In its early stages, critics of New Jersey's ACO legislation claimed that it was essentially "Obamacare." Although the bill upheld many principles of Obama's namesake legislation, its focus on aligning incentives in a way that fosters provider collaboration and engagement, information sharing, and patient input allows each ACO region to develop a model that addresses the unique needs and strengths of its community. The idea of local control helped to ease apprehension among providers that the bill's requirements would put even more pressures on already scarce resources for the Medicaid population.

Brenner and his partners in Trenton and Newark felt that gainsharing was the best solution to incentivize providers and help ensure the long-term sustainability of the ACO model. The bill's emphasis on patient satisfaction and outcomes caused some apprehension among providers, both in terms of the financial implications and because it would require substantial changes in the practice of medicine. The Centers for Medicare and Medicaid Services was concerned about the potential for patient "dumping" as providers assumed greater responsibility for their patients' care and outcomes. Hospitals and other provider organizations (eg, Federally Qualified Health Centers) worried about the legislation's impact on their funding, systems, and processes. However, the authors and sponsors of the bill felt strongly that accountability for patient outcomes was the future of medicine. 
Because the legislation had potential for wide-ranging impact, it was critical to ensure the involvement of all of the relevant stakeholders. Securing this engagement was challenging, time-consuming, and difficult, but it also was imperative to the ultimate success of the bill. Each community presented unique circumstances and suffered from its own political and territorial issues.

Jacobi, Steinhagen, and Litten identified some key issues that should be kept in mind for communities to consider as the demonstration project unfolds:

1. Good relationships are critical to the success of this initiative, and progress is at different stages in each of the 3 regions referenced in this article (Camden, Trenton, and Newark). An extremely high level of cooperation is necessary, and the depth, character, and nature of the relationship building required cannot be overstated.

2. Medical anthropology (examining how a community is organized with regard to health, health care, and related issues) is at the root of this framework; it is not based simply on delivery of health care services.

3. Broad representation across clinical disciplines is necessary; however, there is a big difference between representation from all levels of providers and having all providers in a given category participate in the system. Representation from all levels of providers is key to care coordination, but the emphasis should be on providers who practice good-quality care and follow evidencebased guidelines.

4. Data sharing among clinical providers is essential to ensuring the delivery of good-quality, coordinated care. There are both cultural and technical challenges to the data issues that have yet to be resolved on a large scale.

5. The optimal vision for the demonstration is highly community oriented and based on a shared governance model, wherein those who receive the services have an important voice. In contrast, other models are more technocratic (governance through decision making by experts), which has the potential to create tension.

\section{Unique Community Challenges May Delay Progress}

An illustration of the degree to which "one size does not fit all" is the stalled progress in the city of Newark. Everyone who was interviewed agreed that Newark is far behind Camden and Trenton in terms of ACO development. John Brennan, MD, MPH, president and chief executive officer (CEO) of Newark Beth Israel Medical Center and Children's Hospital of New Jersey, and executive director of the Greater Newark Health Care Coalition, provided some valuable background and perspective as to why it has been so difficult to gain traction in Newark and why it most likely will remain that way for the foreseeable future: there is a higher percentage of the population living in poverty, many with little access to care; uncertainty regarding the stability of care delivery environments (hospitals closing or merging); and the specific financial challenges this combination presents.

\section{Fundamental issues to be addressed}

The Greater Newark Health Care Coalition (GNHCC) is a 501(c)(3) organization committed to improving health outcomes, eliminating disparities, and delivering cost-effective care. It was created through a \$2 million grant from the New Jersey Hospital Association-after 2 Newark hospitals closed in 2009, leaving Newark Beth Israel, St. Michaels, and University Hospital - to address population health issues facing the city (redirecting primary care from emergency rooms to PCMHs). GNHCC is comprised of the CEOs of Greater Newark's hospitals and Federally Qualified Health Centers; city, county, and state elected officials; primary care providers; behavioral health providers; health care lawyers; social workers; patient advocates; and representatives of the state and city departments of health. GNHCC supported the implementation of accountable care for the state, and worked alongside Camden and Trenton to construct the initial legislation.

Before Newark can progress toward development and implementation of its ACO, it must address the following challenges: the transitional state of the Newark hospitals, including the sale and merger of 2 of the hospitals and the struggle to develop a payment structure to support this transition; the increased population to be serviced by these remaining hospitals; and the lack of start-up funding. It has been extremely difficult to create a functional framework with the amount of flux and instability in Newark's health ecosystem. It is the largest of the urban centers (population more than 3 times larger than either Camden or Trenton). Other complicating factors include issues of poverty and access: $30 \%$ of Newark's citizens live below the poverty line and $27 \%$ are without health insurance.

Although Newark has struggled to join Camden and Trenton in their achievements, those who wrote the legislation are confident that the framework of this accountable care model, with coordinated care at its center, is applicable everywhere.

\section{Lessons Learned}

Innovation is particularly difficult to achieve when there are so many stakeholders to be considered, including large government agencies at the state and local level. However, certain elements leveraged by local and statewide champions tipped the scales in favor of the New Jersey ACO legislation. The model itself was ideologically balanced and was promoted as such, allowing for support from social progressives and fiscal conservatives, business interests, and the health care industry. Local control also ensures its relevance and sustainability; it can be tailored to fit the specific needs of each community. Just as important was allowing the individual provider perspective to be offered by smaller physician/nurse practitioner practices.

Based on our conversation with David L. Knowlton (president and CEO) and Allison DeBlois (executive director, Affiliated Accountable Care Organizations) of the New Jersey Health Care Quality Institute, preliminary data indicate that some of the changes being made in preparation for full implementation of the model are already having a positive effect. There is a decrease in emergency department utilization; more important are the individuals whose health is improving. The importance of the inclusion of the following aspects of care cannot be overstressed: family and support systems, and access to food, behavioral health services, and housing. These and other social and economic determinants of health cannot be captured in a quantifiable number for safety net communities. The legacy of New Jersey's ACO legislation has yet to be revealed, but in its infancy it stands as a coordinated care model worth watching. 


\section{Author Disclosure Statement}

Dr. Skoufalos and Ms. Cecil declared the following potential conflicts of interest with respect to the research, authorship, and/or publication of this article: The authors are employed by the Jefferson School of Population Health. The school received financial support from The Nicholson Foundation to conduct the interviews on which this article is based, and to author this manuscript.

\section{References}

1. State of New Jersey Department of Human Services, Division of Medical Statistics and Health Services. Information for Providers and Stakeholders: Accountable Care Organization. <http://www.state.nj.us/humanservices/dmahs/info/aco .html >. Accessed August 22, 2013.

2. Houston R, McGinnis T, Dees B, DeLia D. New Jersey Medicaid ACO Business Planning Toolkit. < http://www .chcs.org/publications3960/publications_show.htm?doc_id = 1261530\#.UcDNY_nVA7k>. Accessed August 22, 2013.

Address correspondence to: Kate Cecil, MS Jefferson School of Population Health 901 Walnut Street, 10th floor Philadelphia, PA 19107

E-mail: kate.cecil@jefferson.edu 